\title{
Formulation of Pulka Using Citrus Limon Peel
}

\author{
Dr. J. Gracia"1, B. Sindhu \\ ${ }^{*}$ Assistant Professor, Department of Food Science and Nutrition, The American College, Madurai, \\ Tamil Nadu, India \\ ${ }^{2}$ Student, Department of Food Science and Nutrition, The American College, Madurai, Tamil Nadu, India
}

\begin{tabular}{|c|c|}
\hline & ABSTRACT \\
\hline $\begin{array}{l}\text { Article History } \\
\text { Accepted : } 01 \text { June } 2021 \\
\text { Published : 04 June } 2021\end{array}$ & 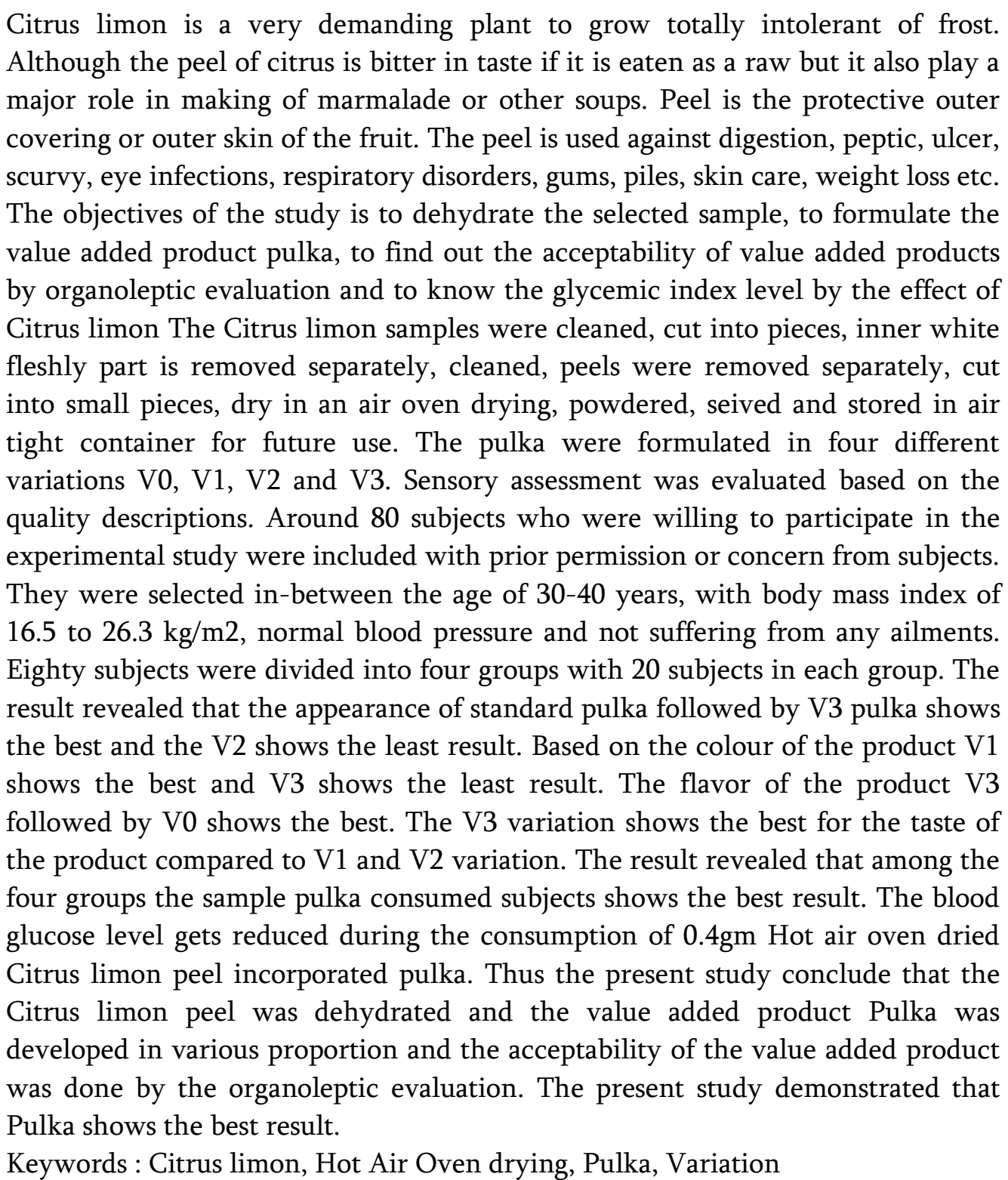 \\
\hline
\end{tabular}

Copyright: (C) the author(s), publisher and licensee Technoscience Academy. This is an open-access article distributed under the terms of the Creative Commons Attribution Non-Commercial License, which permits unrestricted non-commercial use, distribution, and reproduction in any medium, provided the original work is properly cited 


\section{INTRODUCTION}

Lemon is a very demanding plant to grow totally intolerant of frost. The fruit and flowers are destroyed at minus $1-2 \circ \mathrm{C}$ degrees and does it do well in extreme heat. It thrives in areas which are too cool for oranges and grape fruit. The lemon belt is narrow area on the cooler side of orange growing district in both the northen and southern hemispheres. In best conditions the lemon tree produces flowers and fruits almost around the year. The immature fruit is green and during the cool night of autmn and winter the colours turns to yellow. The harvests can be controlled by regulating the irrigation. The main harvesting period is winter and new flowering starts in spring. In dry areas the trees can be left to dry in the summer for 68 weeks until they look shriveled and sickly. When they are then waterted and fertilized heavily a new flowering appears in August - September. The fruit of this flowering will mature in the following summer when lemons are in short supply. The length of the harvest period can be prolonged in this way to increase productivity. In Italy some trees produce four crops a year.

The fruits are used primarily for their juice, though the pulp and rind (zest) are also used, primery in cooking and baking. Lemon juice has about 5\% acids, which gives lemons a sour taste and a $\mathrm{pH}$ of 2-3. This makes lemon juice a cheap, readily available acid for use in educationl science experiments. When ripe, they have a bright yellow nose, a layer of pith underneath and paler yellow segmented interior (Kirtikar and Basu., 1998).

Although the peel of citrus is bitter in taste if it is eaten as a raw but it also play a major role in making of marmalade or other soups. Peel is the protective outer covering or outer skin of the fruit. Botanically it is also called as exocarp. Fruit type like Hesperidium contains very thick type peel. In citrus species the inner and outer part peeled off together and after combining both the parts it is called as peel. The layer which is the juicy part of the fruit is called endocarp. In some of the fruits like apple, pear the peel can be eaten with fruit while fruits like grapefruit, pomegranate and banana the peel should have to be removed before eating of the fruit. In fruit about 25$30 \%$ area covered by the peel and it is wasted by almost everyone. The citrus peel byproduct contains high amount of antioxidants and antimicrobial compounds these can be used as an antioxidant agents or phytochemicals. The wasted peel of citrus contains wide range of biological activities like antiviral, antibacterial, anti-diabetic, anticancer, antifungal etc. The citrus peel generally contains two types of layers, the outermost layer of the peel is called zest and it is made up from citral (5\%) and limonene (90\%). By proper management of the peel we can decrease the level of solid waste and also helps in adding value for this after cutting the outer layer of the peel which is called as zest. Now-a-days it is used as a flavoring agent in biscuits, pies, candies, cakes or chocolates. Citrus peel is very good source of nutrients as it contains phytochemicals and these are Ysitosterol, Bsitosterol, glycosides and volatile oils. Certain flavones, phenolic compounds and ascorbic acid contains special activities. The peel is used against digestion, peptic, ulcer, scurvy, eye infections, respiratory disorders, gums, piles, skin care, weight loss etc (Ali et al., 2017).

The objectives of the study is to dehydrate the selected sample, to formulate the value added product pulka, to find out the acceptability of value added products by organoleptic evaluation and to know the glycemic index level by the effect of Citrus limon

\section{MATERIALS AND METHODS}

The samples used in the study were the Citrus limon peel. The experiment was conducted in a laboratory at the Department of Food science and Nutrition, The American College, Madurai, Tamilnadu. The Citrus limon samples used in this study were obtained from 
the local market Madurai, Tamilnadu. The selected samples were cleaned with tap water to make a sample free from foreign material. The Citrus limon were cut into pieces and the juice of Citrus limon were separated and the inner white fleshly part is removed separately from the yellow peel. Approximate weight of Citrus limon peel were measured before used.

\section{A. Drying of Citrus limon}

The Citrus limon were cleaned, and the peels were removed separately and weighed. The Citrus limon peels were cut into small pieces weighed and dry in an air oven drying for 4 hours. It was turned occasionally for uniform drying. The Dried Citrus limon peel were then weighed and grind into fine powder in an electric grinder, seived and stored in air tight container for future use.

\section{B. Formulation of Pulka}

The pulka were formulated in four different variations ie) V0, V1, V2 and V3. V0 Pulka recipe was formulated using standard procedure which contains $100 \mathrm{gm}$ of whole wheat flour as a base. V1 Pulka was formulated by adding $0.2 \mathrm{gm}$ of hot air oven dried Citrus limon peel flour with the standard ingredient. V2 Pulka was formulated by adding $0.4 \mathrm{gm}$ of hot air oven dried Citrus limon peel flour along with the standard ingredient. V3 Pulka was formulated by adding 0.6gm of hot air oven dried Citrus limon peel flour along with the standard ingredient.

In a wide bowl, add whole wheat flour and required amount of salt and mix them well. Slowly add warm water to the flour mixture and start forming dough. Knead it for few minutes. Cover the dough and let it rest for $10-15$ minutes. Divide the dough into equal sized balls. Dust a dough ball with sufficient flour and start rolling. Place the rolled dough on the hot pan and let it cook for a minute and transfer this directly on to the steel wire grill placed over the flame and let them cook for 2-3 minutes. Then serve hot. C. Sensory Evaluation of the Formulated Product
Sensory assessment was evaluated based on the quality descriptions, i.e. appearance, colour, flavour, taste and texture. Products were evaluated by a panel of 10 semi trained judges from the Department of Food Science and Nutrition, The American College, Madurai. A 9- point hedonic scale ranging from 1 to 9 , where $1=$ extremely dislike and $9=$ like was used to evaluate acceptability of sample.

\section{Statistical Analysis}

Data was analyzed are mean values of each determination \pm standard deviation (SD). Data were analyzed using statistical software of SPSS. The statistical packages for social numbers of sample were carried out for each analysis. The results were expressed as mean \pm standard deviation (SD).

\section{E. Selection of Subjects}

Around 80 subjects who were willing to participate in the experimental study were included with prior permission or concern from subjects. They were selected in-between the age of 30-40 years, with body mass index of 16.5 to $26.3 \mathrm{~kg} / \mathrm{m} 2$, normal blood pressure and not suffering from any ailments

\section{F. Grouping of subjects}

Eighty subjects were divided into four groups with 20 subjects in each group. The purpose of the study was explained to each subject and written consent to participate in the study was obtained. The subjects were given general instructions to avoid any physical exertion, medication, fasts and feasts during the experimental period.

Group I $\quad(\mathrm{N}=20)$ control group without supplementation.

Group II ( $\mathrm{N}=20)$ supplemented with glucose.

Group III ( $\mathrm{N}=20)$ supplemented with standard Pulka.

Group IV (N=20) supplemented with sample incorporated Pulka.

The glucose tolerance test (GTT) was carried out on the overnight fasted subjects with a glucose load of 50 g. Blood samples were collected before feeding ( $0 \mathrm{~min})$ and at 30,60 and 90 min after the test meal was given.

\section{RESULT AND DISCUSSION}




\section{A. Drying of Citrus limon}

The Citrus limon were cleaned, peels removed separately, cut into small pieces, dry in an air oven drying, grind into fine powder and stored in air tight container.

John et al., (2017) was conducting an experiment for evaluating the antioxidant and antimicrobial properties from the peel of citrus lemon. They collected the fresh lemons from the Chennai local market and removed the peel of lemon after washing it and kept it for 4-5 days at room temperature. After that they pulverized the dried peel using an electric blender and used it for methanol and acetone methods of extraction.

Table - 1. Mean and Standard Deviation for the Developed Pulka

\begin{tabular}{|c|c|c|c|c|c|}
\hline & Appearance & Colour & Flavour & Taste & Texture \\
\hline V0 & $8.00 \pm 0.82$ & $8.30 \pm 0.48$ & $7.70 \pm 0.82$ & $7.90 \pm 0.87$ & $8.00 \pm 0.67$ \\
\hline V1 & $8.20 \pm 0.42$ & $8.60 \pm 0.70$ & $7.60 \pm 0.52$ & $8.20 \pm 0.42$ & $8.40 \pm 0.70$ \\
\hline V2 & $8.00 \pm 0.66$ & $8.10 \pm 0.87$ & $7.80 \pm 0.63$ & $8.40 \pm 0.70$ & $8.40 \pm 0.70$ \\
\hline V3 & $8.30 \pm 0.67$ & $7.90 \pm 0.57$ & $7.90 \pm 0.57$ & $8.60 \pm 0.51$ & $8.20 \pm 0.42$ \\
\hline
\end{tabular}

V0 - Standard pulka

V1 - 0.2gm of Hot air oven dried Citrus limon

V2 - 0.4gm of Hot air oven dried Citrus limon

V2 - 0.6gm of Hot air oven dried Citrus limon

\section{B. Formulation of Pulka}

There are four different pulka prepared in various proportion such as standard pulka (V0), 0.2gm Hot air oven dried Citrus limon peel incorporated pulka (V1), 0.4gm Hot air oven dried Citrus limon peel incorporated pulka (V2) and 0.6gm Hot air oven dried Citrus limon peel incorporated pulka (V3).

\section{Sensory Evaluation}

The appearance of standard pulka followed by V3 pulka shows the best and the V2 shows the least result. Based on the colour of the product V1 shows the best and V3 shows the least result. The flavor of the product V3 followed by V0 shows the best. The V3 variation shows the best for the taste of the product compared to V1 and V2 variation. Thus the
V3 ie) $0.4 \mathrm{gm}$ of Hot air oven dried Citrus limon peel shows the best compared to the other.

Color which is a sensation that forms part of the sense of vision, judges the appearance of a food. Therefore, among this color is a one of the most important sensory quality. Attractive color of the end product gives good demand for it (Al-Hooti and Sidhu, 1997). Aroma is an integral part of taste and general acceptance of the food before it is put in the mouth. It is therefore an important parameter when testing acceptability of formulated foods (Dhushane and Mahendran, 2020). Taste is an important parameter when evaluating sensory attribute of food and it has the highest impact as far as market success of product, is concerned (Dhushane and Mahendran, 2020). The most important attribute in food selection is texture that consists of those properties of product which judges visually or by touch. There were significant differences between treatments. Highest mean value (6.30) for jam with 3.3g pectin and poorest mean value (4.92) for formulation with no pectin added to jam. Similar findings in texture were expressed by Ehsan et al., (2002) in grape and apple marmalade.

D.E xperimental Study for the Assessment of Blood Glucose Level

Four groups with 20 subjects in each group such as Group I control group without supplementation, Group II ( $\mathrm{N}=20)$ supplemented with glucose, Group III ( $\mathrm{N}=20)$ supplemented with standard Pulka and Group IV ( $\mathrm{N}=20)$ supplemented with sample incorporated Pulka. were given in the below table

Table - 2. Mean value for the Supplementary Effect of Food assessed using Blood Glucose Level

\begin{tabular}{|l|c|c|c|c|}
\hline & $\mathbf{0}$ mins & $\begin{array}{c}30 \\
\text { mins }\end{array}$ & $\begin{array}{c}60 \\
\text { mins }\end{array}$ & $\begin{array}{c}90 \\
\text { mins }\end{array}$ \\
\hline $\begin{array}{l}\text { Control } \\
\text { group }\end{array}$ & 82 & 85 & 88 & 83 \\
\hline Glucose & 100 & 120 & 166 & 180 \\
\hline $\begin{array}{l}\text { Standard } \\
\text { Pulka }\end{array}$ & 100 & 118 & 128 & 130 \\
\hline Sample Pulka & $\mathbf{9 0}$ & 115 & 110 & 100 \\
\hline
\end{tabular}


The result revealed that among the four groups the sample pulka consumed subjects shows the best result. The blood glucose level gets reduced during the consumption of $0.4 \mathrm{gm}$ Hot air oven dried Citrus limon peel incorporated pulka.

\section{CONCLUSION}

The Citrus limon peel was dehydrated and the value added product Pulka was developed in various proportion and the acceptability of the value added product was done by the organoleptic evaluation. The present study demonstrated that Pulka shows the best result.

\section{REFERENCES}

[1]. Ali, J, Das, B and Saikia. (2017). Antimicrobial activity of lemon peel (Citrus limon) extract. International Journal of Current Pharmaceutical Research, 9(4), 79-81.

[2]. John, S., Monica, S. J., Priyadarshini, S., Sivaraj, C., and Arumugam, P. (2017). Antioxidant and antimicrobial efficacy of lemon (Citrus limonum L.) Peel. Int. J. Pharm. Sci. Rev. Res, 46(1), 115118.

[3]. Kirtikar K.R and Basu B.D (1998) "Indian Medicinal Plants" 2(1); Bishen Singh Mahendra Pal Singh, Dehradun.

[4]. Al-Hooti, S., Sidha, J., Alotaibai, J., Al Ameeri, H. and Qabazard, H. 1997. Processing quality of important date cultivars grown in the United Arab Emirates for jam, butter and dates in syrup. Advances in Food Science and Technology. 32: 35-40.

[5]. Dhushane S and T. Mahendran, 2020. Extraction of Pectin from Lemon (Citrus limon L.) fruit peels and its utilization in the Production of Watermelon (Citrullus lanatus) Jam, Journal of the University of Ruhuna Volume 8 No 1, May 2020. Pp 49-59.

[6]. Ehsan, E. B., Naeem, Z. P., Ghafoor, A. and Bahtti, M. S. 2002. Development, standardization and storage studies on watermelon lemon jam. Pakistan

\section{Cite this article as :}

Dr. J. Gracia, B. Sindhu, " Formulation of Pulka Using Citrus Limon Peel", International Journal of Scientific Research in Science and Technology(IJSRST), Print ISSN : 2395-6011, Online ISSN : 2395-602X,Volume 8, Issue 3, pp.498-502, May-June-2021. Available at doi $\quad:$ https://doi.org/10.32628/IJSRST2183104 Journal URL : https://ijsrst.com/IJSRST2183104 